\title{
Fibrin glue for Gundersen flap surgery
}

This article was published in the following Dove Press journal:

Clinical Ophthalmology

5 March 2013

Number of times this article has been viewed

\author{
Hsi-Wei Chung' \\ Jodhbir S Mehta ${ }^{\mathrm{I}-3}$ \\ 'Singapore National Eye Centre, \\ Singapore; ${ }^{2}$ Tissue Engineering \\ and Stem Cell Group, Singapore \\ Eye Research Institute, Singapore; \\ ${ }^{3}$ Department of Clinical Sciences, \\ Duke-NUS Graduate Medical School, \\ Singapore
}

Purpose: To evaluate the feasibility of fibrin glue in Gundersen flap surgery.

Design: Prospective case series.

Study subjects: Seven eyes of seven subjects who had undergone Gundersen flap surgery from 2009 to 2011 at the Singapore National Eye Centre, Singapore.

Methods: Review of case records for outcomes after Gundersen flap surgery.

Main outcome measures: Surgical success was defined as achieving a stable ocular surface. Complications to be noted included flap retraction or exposure of underlying corneal surface.

Results: Surgical success was achieved in all eyes with significant reduction in ocular surface inflammation. No retractions were noted and recovery was uncomplicated.

Conclusion: Fibrin glue application is a viable alternative to sutures in Gundersen flap surgery. It reduces surgical downtime, gives faster ocular surface rehabilitation, and offers similar outcomes to conventional conjunctival flap surgery.

Keywords: Gundersen, conjunctival flap, fibrin glue

\section{Introduction}

The use of conjunctival flaps to resurface an irregular corneal surface was first proposed by Gundersen in 1958. ${ }^{1,2}$ The indications for conjunctival flaps include herpetic keratitis, bullous keratopathy, neuroparalytic keratopathy, progressive nonhealing epithelial defects, chronic infectious keratitis, corneal melts, and perforations. ${ }^{3}$

Gundersen flap surgery, therefore, has an established role in providing a stable ocular surface and suppressing inflammation in damaged corneas or eyes with poor visual potential. This also achieves the secondary purpose of pain relief, reduction in topical anti-inflammatory medications, and provides an alternative to evisceration.

Lim et $\mathrm{al}^{4}$ evaluated the largest series of long-term outcomes with Gundersen flap surgery in 2009. Even though surgical success was achieved in all of their patients, complications were encountered in $24 \%$, including buttonholes, partial flap retractions, and epithelial inclusion cysts. The most common complication reported was flap retraction, with rates varying from $11.4 \%$ to $85 \%$ in the literature. ${ }^{3,5}$ The cause of flap retraction was attributed to inadequate mobilization of the harvested graft or insufficient suturing.

Suturing is one of the most crucial steps and the key to the success of this procedure. The flap over the cornea should be neither too tight nor too loose. Sutures that are too tight may cheese wire through a tight conjunctival flap. Conversely, a loose flap will not heal and may detach during the postoperative period.
Correspondence: Jodhbir S Mehta Singapore National Eye Centre, II Third Hospital Avenue, Singapore I6875 I

Tel +656322831 I

Fax +6563231903

Email jodmehta@gmail.com 
The use of fibrin glue has been well established in ophthalmology and well documented following pterygium surgery. ${ }^{7,8}$ Panda et $\mathrm{al}^{6}$ have described its use for conjunctival closure in pterygium and strabismus surgery, in corneal melts or perforation, amniotic membrane transplants, corneal grafts, treating epithelial in-growth in refractive surgery, managing postoperative leaking blebs, lids, and orbital surgery.

Fibrin glue-assisted pterygium surgery has been found to be superior to sutures with conjunctival autografting as it reduces pterygium recurrence without increasing complication rates and is associated with a significantly faster surgical time coupled with a reduction in the intensity of postoperative pain, foreign body sensation, and epiphora. ${ }^{8}$ This also allows for quicker rehabilitation post-surgery. ${ }^{6}$

To the best of our knowledge, there are no studies to date on the use of fibrin glue in Gundersen flap surgery, where more surgical expertise and time is required to mobilize a large conjunctival flap to ensure adequate corneal coverage.

The aim of this study was thus to evaluate the feasibility, complications, and outcomes of Gundersen flap surgery using fibrin glue.

\section{Methods}

This was a prospective case series of patients who had undergone Gundersen flap surgery from January 2009 to June 2011 at the Singapore National Eye Centre, Singapore.

Surgery was performed by a single surgeon (JSM), and surgical success was defined as having achieved a stable ocular surface with no flap retraction, dehiscence, or exposure of the underlying corneal surface.

Patients with poor visual prognosis, requiring surgery for stabilization of the ocular surface or for pain relief were included in this study. Patient demographics, indications for surgery, surgical outcomes, and intraoperative and postoperative complications were documented. Operative technique was reviewed from the surgical records and any subsequent surgery was also noted. All patients were given a topical steroid and antibiotic eye drop in the early postoperative period after the primary procedure on a tapering dose for 3 months. The study was performed in accordance with the tenets of the Declaration of Helsinki as revised in 1989. The study had internal review board approval from the Singapore National Eye Centre, Singapore Eye Research Institute, Singapore.

\section{Fibrin glue preparation}

Commercially available fibrin glue (Tisseel VH; Baxter AG, Vienna, Austria) was prepared according to the manufacturer's instructions, whereby free-dried sealer protein concentrate and thrombin were reconstituted in fibrinolysis inhibitor solution and calcium chloride solution, respectively, and were warmed in a patented fibrinotherm device. After reconstitution of the powder, $1 \mathrm{~mL}$ of thrombin solution contained $4 \mathrm{IU}^{3}$ of thrombin.

\section{Surgical technique}

Surgery was performed under regional anesthesia with a peribulbar block. Placement of a superior clear cornea 7.0 silk traction suture was followed by corneal epithelium debridement (including areas of dystrophic calcification, surface deposits, and pterygia) (Figure 1) with a pterygium blade (Bard Parker 64 blade).

The affected corneal surface was premeasured to ensure adequate coverage prior to superior bulbar conjunctival
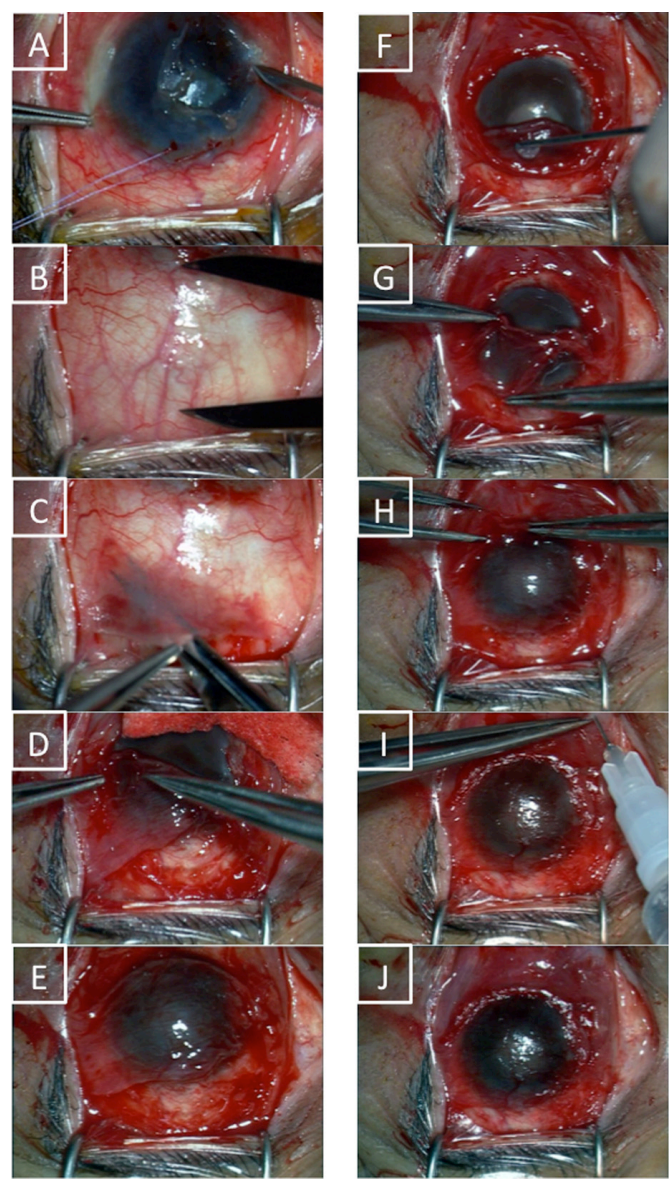

Figure I Corneal epithelium debridement $(\mathbf{A})$ is followed by pre-measurement of the size of the conjunctival autograft required (B). After bulbar conjunctival dissection (C), a 270-degree limbal peritomy with two 45-degree relaxing incisions at 5 and 7 o'clock was performed with limbal diathermy. The flaps were mobilized over the corneal surface (D) and inferior conjunctiva was dissected (E) to ensure better corneal coverage if needed (this was especially so in eyes with scarred superior conjunctiva secondary to glaucoma drainage devices). Fibrin glue was then applied to the underside of the graft $(\mathbf{F})$ and the flap was positioned epithelium-side up $(\mathbf{G})$. The flap edges are later opposed $(\mathbf{H})$ and subconjunctival injections of steroids and antibiotics are given at the end of the procedure (I). The final result is as shown in (J). 
flap harvesting. Inferior bulbar conjunctiva was harvested in addition when superior conjunctiva was too scarred (eg, in the presence of glaucoma-drainage devices).

Dissection of the superior bulbar conjunctiva was performed in stages using Vannas scissors. First, this was extended temporally and nasally, above the horizontal recti muscles. This allowed mobilization of the free conjunctiva from 10 to 2 o'clock with minimal inclusion of the underlying Tenon tissue. The aim was to ensure as thin a conjunctival flap as possible for greater transparency and to reduce fibrotic contraction. Care was taken not to create buttonholes, especially in the central area that would be covering the corneal surface. The amount of dissection was estimated to be equivalent to the vertical corneal diameter to the superior limbus plus $2 \mathrm{~mm}$.

A $360^{\circ}$ limbal peritomy was performed, ensuring removal of the limbal and pannus epithelium to prevent epithelial cyst formation. The harvested flap was mobilized over the corneal surface. Limbal stem cell ablation was performed with a diathermy. The inferior conjunctival peritomy between 5 and 7 o' clock was undermined to allow freer mobilization superiorly.

The superior conjunctival flap was mobilized inferiorly and the inferior conjunctival flap superiorly, and both were inverted to expose the stromal surface of the flap. The thrombin solution was placed on the stromal side of the flap bed. Sealer protein concentrate containing fibrinogen was then placed on the corneal surface and then laterally dissected over the areas. Both the temporal and nasal areas as well as the flaps were subsequently reflected stromal-side-down on the ocular surface. The superior flap was gently spread to ensure coverage of the entire cornea surface and the inferior border of the superior flap was apposed to the superior border of the inferior flap with conjunctival forceps. Subconjunctival injections of steroid (dexamethasone) and antibiotic (cefazolin and gentamicin) eye drops were given at the end of surgery.

Postoperatively, steroid (preservative-free dexamethasone minims) and antibiotic (levofloxacin) eye drops were given in tapering doses for a total of 3 months.

Surgical success was defined as attainment of a stable ocular surface with resolution of symptoms and no flap retraction or dehiscence resulting in re-exposure of the corneal surface. Complications noted included infection, progression of the infectious/inflammatory disease process beneath the flap, and epithelial cyst formation. A visual analog scale was used for grading of pre- and postoperative (at 1 month) pain. Patients would rank their pain as none (scale 0), mild (1-3), moderate (4-6), or severe (7-10). A similar scale was used to score ocular inflammation at postoperative day 1 and at 3 months.
Data was analyzed using SPSS software (IBM Corporation, Armonk, NY, USA). Mann-Whitney U tests were used for nonparametric comparisons of operating times between the fibrin glue and suture groups while Wilcoxon signed rank tests were used for pre- and postoperative visual analog and inflammation comparisons. Statistical significance was assumed at $P<0.05$.

\section{Results}

Seven eyes of seven patients were evaluated. All patients (three males and four females) were of Chinese ethnicity. The mean age of the patients was $68.2 \pm 10.1$ years (range 52.6-83.4 years) and the mean duration of follow-up was $20 \pm 5.2$ months (range 11.9-27.4 months).

Preoperative visual acuity was hand movements in one eye, perception of light in four eyes, and no perception of light in two eyes. Visual acuity was also unchanged postoperatively for five patients and improved in two patients. Patient demographics are summarized in Table 1.

In a comparison of operating times by other cornea surgeons in the same center during the same and preceding 5-year period, the median operating times in the fibrin glue $(n=7)$ and suture $(n=6)$ groups were 30 minutes and 49.5 minutes, respectively. The difference in distributions in these two groups were statistically significantly (MannWhitney $\mathrm{U}=38.5, P=0.014$ [two-tailed]).

The mean operating times in the fibrin glue group was 31 minutes (standard deviation [SD] 7.0, range 19-43 minutes) while that of the sutures group was 46 minutes (SD 10.6, range 31-60 minutes).

Surgical success (ocular surface stability and resolution of symptoms) was achieved in all eyes with significant reduction in ocular surface inflammation as well as a significant improvement in the visual analog pain scale $(P=0.016)$. The mean pain score out of 10 was 7 (SD 1.4) preoperatively and 0 (SD 0.5 ) at 1 month post-surgery. Postoperative inflammation at day 1 was a mean of 8 (SD $0.5)$, largely due to conjunctival injection, although patients did not experience much discomfort. This had reduced significantly $(P=0.016)$ to a mean of $3(\mathrm{SD} 0.5)$ at the end of the 3rd month.

There were no intra- or postoperative complications. One patient had inferior flap advancement due to superior scarring secondary to glaucoma shunting device superiorly. No patients reported significant postoperative pain on day 1 after surgery (mild pain or visual analog scale $>3$ ). No retractions were noted and recovery was uncomplicated. Figure 2 depicts the postoperative recovery process in three patients. 


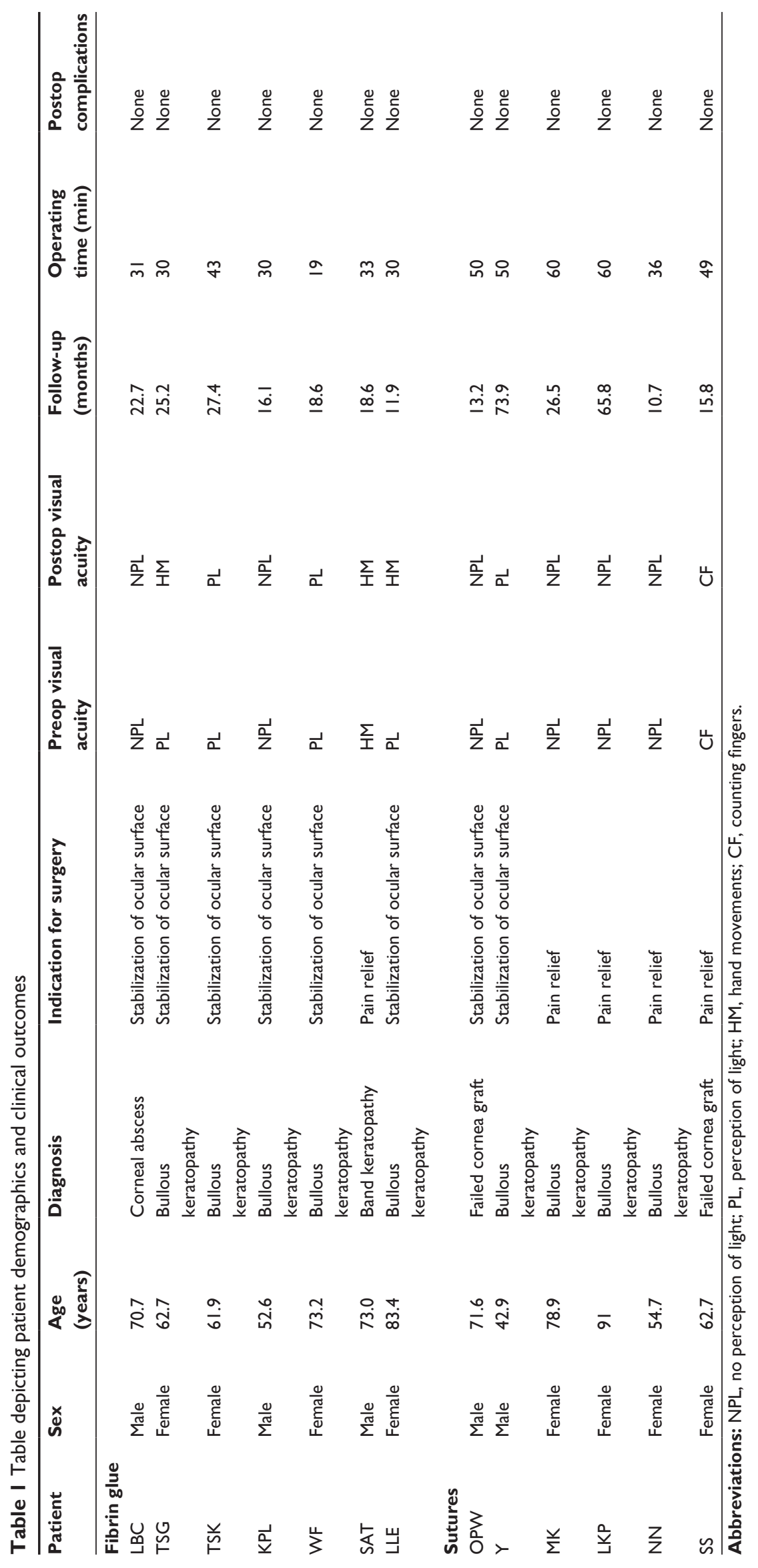


Patient A (TSG)

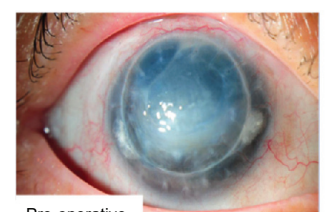

Pre-operative

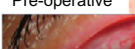

A. .8

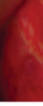

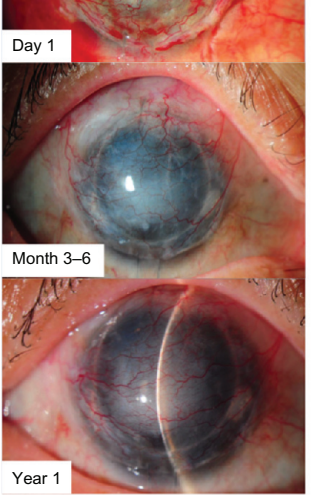

Figure 2 Pre- and postoperative recovery (up to I year) of two patients after Gundersen flap surgery with fibrin glue.

Notes: Patient A (TSG) had a failed cornea graft with bullous keratopathy. Patient B (TSK) had bullous keratopathy secondary to glaucoma. She had a filtration tube under her superior temporal conjunctiva; hence she needed an advancement of her inferior conjunctiva to ensure complete closure of the corneal surface.

\section{Discussion}

The use of Gundersen flaps, though efficacious, is an underutilized option for stabilization of the ocular surface. Alternative therapeutic options including amniotic membrane transplantation, and extended wear bandage contact lenses, have resulted in a decline in the popularity of conjunctival flaps as an option for ocular surface rehabilitation. ${ }^{4}$ However, the risk of infection and the long-term durability of the latter options still make Gundersen flaps a viable and cost effective option for patients.

There are inherent challenges in harvesting an adequately thin, large sized conjunctival flap for adequate corneal coverage. This needs to be coupled with proper suturing techniques to prevent graft dehiscence in the postoperative period. Therefore the use of fibrin glue in this setting (as an adhesive to keep the Gundersen flap in place) allows the surgeon less tissue manipulation, good tissue closure and reduces surgical time versus sutures. In addition, the fibrin sealant used was employed with the available low concentration of thrombin $(4 \mathrm{IU} / \mathrm{mL})$ as opposed to the available higher level of thrombin $(500 \mathrm{IU} / \mathrm{mL})$ in order to slow the rate of polymerization of the material and allow time for flap placement and manipulation.
Although the use of fibrin glue in conjunctival surgery has been well defined in the literature, its use in Gundersen flap surgery has not been described before. To our knowledge, this is the first case series reporting its novel use in Gundersen surgery with a sufficiently long mean follow-up time of 20 months (the majority of complications following Gunderson flap surgery occur within the first 9 months).

The advantages of using fibrin glue were a reduction in surgical time, less postoperative pain, and a good cosmetic outcome, with resorption leaving minimal scarring. In addition, with no sutures to incite additional inflammation, patient rehabilitation was fast. Our series has demonstrated similar if not superior surgical outcomes with respect to conjunctival flap retractions compared to published series with sutures. ${ }^{4}$ The authors in the published series as well in our comparison group for this study are other surgeons in the same eye center. The postoperative medication given to both groups is the same. However, we understand that further validation of these results would require a randomized control trial with a single surgeon.

\section{Conclusion}

Fibrin glue application is a viable alternative to sutures in Gundersen flap surgery. It reduces surgical downtime, gives faster ocular surface rehabilitation, and offers similar outcomes to conventional conjunctival flap surgery.

\section{Disclosure}

The authors report no conflicts of interest in this work.

\section{References}

1. Gundersen T. Conjunctival flaps in the treatment of corneal disease with reference to a new technique of application. AMA Arch Ophthalmol. 1958;60(5):880-888.

2. Gundersen T, Pearlson HR. Conjunctival flaps for corneal disease: their usefulness and complications. Trans Am Ophthalmol Soc. 1969;67: 78-95.

3. Alino AM, Perry HD, Kanellopoulos AJ, Donnenfeld ED, Rahn EK. Conjunctival flaps. Ophthalmology. 1998;105(6):1120-1123.

4. Lim LS, How AC, Ang LP, Tan DT. Gundersen flaps in the management of ocular surface disease in an Asian population. Cornea. 2009;28(7):747-751.

5. Paton D, Milauskas AT. Indications, surgical technique, and results of thin conjunctival flaps on the cornea: a review of 122 consecutive cases. Int Ophthalmol Clin. 1970;10(2):329-345.

6. Panda A, Kumar S, Kumar A, Bansal R, Bhartiya S. Fibrin glue in ophthalmology. Indian J Ophthalmol. 2009;57(5):371-379.

7. Suzuki T, Sano Y, Kinoshita S. Conjunctival inflammation induces Langerhans cell migration into the cornea. Curr Eye Res. 2000;21(1): 550-553.

8. Karalezli A, Kucukerdonmez C, Akova YA, Altan-Yaycioglu R, Borazan M. Fibrin glue versus sutures for conjunctival autografting in pterygium surgery: a prospective comparative study. Br J Ophthalmol. 2008;92(9):1206-1210. 


\section{Publish your work in this journal}

Clinical Ophthalmology is an international, peer-reviewed journal covering all subspecialties within ophthalmology. Key topics include: Optometry; Visual science; Pharmacology and drug therapy in eye diseases; Basic Sciences; Primary and Secondary eye care; Patient Safety and Quality of Care Improvements. This journal is indexed on

Submit your manuscript here: http://www.dovepress.com/clinical-ophthalmology-journal
PubMed Central and CAS, and is the official journal of The Society of Clinical Ophthalmology (SCO). The manuscript management system is completely online and includes a very quick and fair peer-review system, which is all easy to use. Visit http://www.dovepress.com/ testimonials.php to read real quotes from published authors. 